\title{
¿Cacique, general y hacendado? Transformaciones en la dinastía Catriel, Argentina, 1820-1870
}

\author{
Marcelino Irianni \\ IEHS - CONICET
}

El avance colonizador del mundo blanco sobre el territorio indígena pampeano (Argentina) durante el siglo XIX impactó diferencialmente sobre las parcialidades que allí habitaban. En el caso que aquí se analiza, perteneciente a las "tribus amigas", el proceso activó distintos mecanismos de acercamiento destinados a conseguir un reacomodamiento que les asegurara la supervivencia en la región. Éstos resultaron, sin ninguna duda, muy exitosos en el corto plazo. Las transformaciones socio-económicas, políticas y culturales que afectaron a la dinastía de los Catriel desmienten al menos dos fenómenos fuertemente relacionados entre sí. La idea de inmutabilidad del mundo aborigen es uno; el papel central de lo étnico en la toma de sus decisiones, el otro.

PALABRAS CLAVE: Indios amigos, etnicidad, acomodamiento, aprovisionamiento, hacendado, negociación.

The colonizing advance of the white world on native in the Pampas of Argentine territory during the XIX century affected in different ways the peoples who inhabited the area. In the case analized, one of "friendly tribes", the process initiated different mechanisms destined to lead to readjustment that guaranteed survival in the region. These became doubtlessly very successful in the short term. The socio-economic, political and cultural transformations that affected the Catriel dynasty refute at least two closely related phenomena. Firstly, the idea of the immutability of the indigenous world; and secondly, the role ethnicity played in the decision-making process.

KEYWORDS: Friendly Indians, ethnicity, adjustement, provisioning, large landholder, negotiation.

Resulta inevitable, cuando uno intenta situarse en el escenario aborigen pampeano del siglo XIX, hacerlo filtrando la información —o intentando sintetizarla para hacerla comprensible- a través de distintas categorías y conceptos. Tribus, indios amigos, caciques, jefaturas son sólo algunos de ellos. ${ }^{2}$

1 Este trabajo, en una versión preliminar, fue presentado en las Jornadas sobre Biografía e Historia, IEHS, UNICEN, Tandil, 28 y 29 de noviembre de 2002.

2 Mandrini, Raúl: "Indios y fronteras en el área pampeana (siglos XVI-XIX): balances y perspectivas" en Anuario del IEHS, 7, UNCPBA, Tandil, 1992; Ratto, Silvia: "El negocio pacífico de los indios: La frontera bonaerense durante el gobierno de Rosas", en Siglo XIX. Revista de Historia, n. ${ }^{\circ}$, Instituto Mora, México, 1994; y Palermo, Miguel Ángel: "Reflexiones sobre el llamado "complejo ecuestre' en la Argentina en RUNA", Archivo para las ciencias del Hombre, vol XVI, ICA/UBA, Buenos Aires, págs. 157-178., son algunos de los autores que han intentado calibrar un poco más la conceptualización de que hablamos. 
Sin embargo, al momento de ejemplificarlos con figuras o grupos determinados, surge rápidamente que han servido para resolver situaciones no poco dispares. ¿Qué es un cacique? ¿Es lo mismo en 1820 que en 1860? ¿Catriel y Calfucurá se ajustan igualmente a dicho concepto? A presentar este problema e intentar avanzar algo en la clarificación de estas categorías - a priori sumamente flexibles - se dedica parte de las próximas páginas. Se trata, claro está, de avanzar en pos de que los conceptos, alguna vez útiles, no almidonen nuestros caminos hacia reconstrucciones más ajustadas a la realidad histórica. Sin ir más lejos, estamos comenzando a repensar hasta qué punto tuvo un papel preponderante el factor étnico en las relaciones de frontera; idea totalmente descabellada hace apenas una década. Del mismo modo, tenemos que trasladar conceptos claramente destinados al mundo blanco para su verificación en las sociedades aborígenes; nociones como hacendados o productor absentista son ejemplos a la mano que ilustran el accionar de algunos representantes de la dinastía que tratamos.

Seguidamente se analizará el caso de Catriel, desde una perspectiva diacrónica, para rastrear cambios experimentados que harían dudar de su condición de cacique -incuestionable en 1840 - al final de sus días. Reconstruir la biografía de una persona ajena al mundo de los registros y que deambuló parte de su vida por espacios alejados de la escritura personal y de quienes podían observarle se presenta como un desafío. Éste cobra un interés mayor en tanto y en cuanto nos permita recuperar sus estrategias en pos de un horizonte mayor, al mismo tiempo que se operaba la oportuna mutación de sus roles, a medida que cambiaba la situación personal de cada cacique, resultando de distintas coyunturas socio-económicas y políticas. Juan Catriel 'el Viejo', su hijo Juan Segundo y posteriormente sus nietos Cipriano y Juan José ensayaron, desde 1820 y hasta 1870, un proceso que lejos de ser una estrategia de largo alcance se puede visualizar como una serie de pequeños acomodamientos a distintas situaciones que se les presentaban.

La segunda cuestión a abordar, íntimamente ligada a la anterior, tiene que ver con la posibilidad de que alguna de esas categorías presenten transformaciones a lo largo del período en cuestión, que muchas veces desdibujan el status original pero no terminan de definir uno nuevo, aunque sí cierta dirección hacia un rol diferente. Nos referimos, por ejemplo, a aquellos caciques como Catriel que a mitad del XIX se asemejan a verdaderos hacendados, aunque sin abandonar del todo su faceta étnica ni formar parte decisiva de la elite ganadera nativa. 
Efectivamente, Catriel se convierte al final de sus días en un hacendado y su gente funciona como una verdadera clientela política que le sirve principalmente para conseguir favores del poder de turno. Los abastecimientos que le otorga el Estado cada tres meses a cambio de mantener la paz y colaborar con el ejército - desarmando el malón como empresa económica - le permiten mantener momentáneamente la situación de hacendado absentista - ya que vive en pleno centro de Azul - y una clientela de un millar de lanzas. Clientela imposible de convertirse, como en parte lo hizo Colliqueo, en peonada que se desmembrara en estancias de la zona o puestos de trabajo en la ciudad. ${ }^{3}$ El mercado de trabajo estacional lentamente ocupado por inmigrantes no lo permitía, al margen de si los indios fueran o no aceptados como trabajadores. Pero si hubiera sido posible, difícilmente Catriel lo habría alentado, ya que era su cuota de poder ante sus pares terratenientes. Un cacique sin indios era tan intrascendente y abstracto como un hacendado sin ganado o un general sin soldados.

Por otro lado, sostenemos nuestra idea de que Catriel estaba obligado a alternar en dos mundos distintos sin terminar de traspasar al que cada vez le atrapaba más, el de los blancos. Situación idéntica a la experimentada cien años antes por Tupac Amaru, que frecuentaba la sociedad española en casi todos sus ámbitos, pero no renunciaba a su ascendente sobre los suyos que seguían reconociendo su linaje indígena. Así, pese a aceptar las charreteras y el quepi, a cambiar sus botas de potro por otras de caña larga o dejar el caballo por una volanta, Catriel pudo presidir (cada vez con más dificultades y menos regularidad) una ceremonia indígena, tener varias esposas y ser uno más entre su gente.

La situación de Catriel también se asemeja, sin mucho esfuerzo, a la de ciertos inmigrantes en la misma Argentina, que luego de lograr una posición económica holgada intentaron cohesionar a sus paisanos para contar con un elemento de presión ante la elite nativa que les negaba un espacio sociopolítico. El problema de Catriel fue, en definitiva, que sus indios no alternaban como la masa inmigrante en los dos mundos en los que él se movía; eran sólo indios. Caminar por el borde del precipicio era una jugada riesgosa y cada uno de los representantes de la familia debió saberlo; cada paso en

3 Nos referimos a una inserción masiva en el mercado, que por otra parte estuvo en formación durante buena parte del siglo XIX. Sabemos, de todos modos, de indios que trabajaban temporalmente e incluso en forma permanente en las estancias desde la segunda década de ese siglo. Ver, entre otros, Ratto, Silvia: “¿Soberanos, clientes o vecinos? Algunas consideraciones sobre la condición de los indígenas en la sociedad bonaerense", en Villar, Daniel, Jiménez, Juan Francisco y Ratto, Silvia: Conflicto, poder y justicia en la frontera bonaerense, 1818-1832, Bahía Blanca, 2003. 
dirección hacia el mundo blanco los debilitaba internamente como jefes, e incluso ante las otras parcialidades; irónicamente, esto último era un pilar básico de los Catriel para oscilar en las márgenes de la civilización.

La identidad de los catrieleros debió terminar de conformarse, como dice Boccara, ${ }^{4}$ a la par de los contactos con la sociedad blanca. Esto no implica pensar que no se reconocieran linajes, ámbitos y ligazones de pertenencia reales; lo que queremos apuntar es que si partimos de nuestra idea de que todos los grupos pertenecen naturalmente a una ciudad, una región, una nación, un Estado y un continente, nos resultará difícil comprender y aceptar la posibilidad de que algunas parcialidades indígenas terminaran de construir y/o fortalecer una identidad más clara en el proceso de interacción con los blancos. Si, por el contrario, estamos de acuerdo con la idea de Boccara, que las distintas posturas recrudecieron un proceso de atomización de la pampa en etnias anteriormente no tan diferentes ni enemistadas entre sí, también coincidiremos en que la coyuntura decimonónica con un Estado en formación y el avance de la frontera fueron los pilares básicos para que aparecieran personajes como los Catriel.

\section{Catriel, el cacique amigo de la pampa}

Catriel nace alrededor del septuagésimo año del siglo XVIII en los pagos de Tapalqué, en algún lugar de los actuales partidos del mismo nombre y Olavarría. ${ }^{5}$ Con el tiempo se convierte en el fundador de la dinastía catrielera. Juan Catriel 'el Viejo' tuvo como su segundo a Cachul, ambos eran jefes de tribus, antes de reducirse en Salinas Grandes, con Ripil, Carupan, Cañumil, Tripallao y otros. ${ }^{6}$

Las primeras referencias importantes de Catriel en territorio pampeano lo ubican en la década de 1820 llevando a cabo algunas correrías junto a los caciques Calfiau y el gaucho Molina. ${ }^{7}$ Sin embargo, algo sucede al empezar la segunda década del siglo XIX. Cuando Rauch recorre la zona centro sur en 1826, lo acompañaban en calidad de aliados un regular contingente de indios pertenecientes a su tribu. Cinco años más tarde, el día 3

4 Boccara, Guillaume: "Fronteras, mestizaje y etnogénesis en las Américas", en Mandrini, Raúl y Paz, Carlos (comp.): Las fronteras hispanocriollas del mundo indígena latinoamericano en los siglos XVIII-XIX”, Artes Gráficas Limay, Neuquén, 2003, pág. 74 y ss. Aires, 1974

5 Cuadrado Hernández, G.: "La dinastía de los Catriel" en Todo es Historia, n. ${ }^{\circ}$ 1, Buenos

6 Del Valle, Antonio G.: Recordando el pasado,, Azul, 1926.

7 Muñiz, Rómulo: Los indios pampas, Ed. Bragado, Buenos Aires, 1966, págs. 123-124. 
de abril de 1833, la columna izquierda de la campaña al desierto comandada por Rosas alcanza las márgenes del arroyo Tapalqué, donde los voroganos, al tener conocimiento de su marcha, enviaron algunos caciques de sus tribus en signo de amistad. ${ }^{8}$ Allí se incorporaron las tribus de los caciques amigos Catriel, Cachul, Llanquellen, Fracaman, Reilet, Cayupán y otros que, con 600 indios más, concurrieron como auxiliares de la expedición. ${ }^{9}$

En 1835, ubicado a orillas del arroyo Tapalqué, era ya un inconfundible aliado del gobierno porteño. Su gente participó el 7 de noviembre de 1839 de las acciones bélicas en Chascomús y ayudó al Restaurador contra la Revolución de los Libres del Sud. ${ }^{10}$ Catriel 'el Viejo' era no sólo confiable para el gobernador Rosas sino modelo y referencia al momento de acercar a otros caciques. A tal punto que en una cláusula del Tratado de Paz con Painé en 1840 se dice: "puede venir Painé o algunos casiques a Tapalqué a verse con Catrié y demás casiques amigos míos, para oír de bocas de ellos quien soy yo". ${ }^{11}$ Esa amistad se traducía en bienes que un Estado improvisado entregaba a Catriel en forma periódica. En 1845 esa ración constaba de lo siguiente:

\begin{tabular}{|c|c|}
\hline 1 docena tarros de ginebra. & 40 \\
\hline 10 arrobas tabaco negro $\ldots \ldots \ldots \ldots \ldots \ldots \ldots$ & 50 \\
\hline 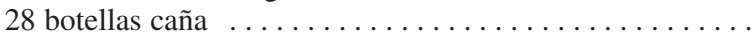 & 140 \\
\hline 20 pesos jabón negro $\ldots \ldots \ldots \ldots \ldots \ldots \ldots \ldots \ldots$ & \\
\hline 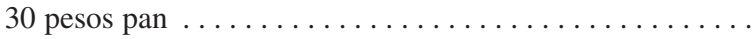 & \\
\hline 4 mantas de paño punzó buenas $\ldots \ldots \ldots \ldots \ldots \ldots$ & 160 \\
\hline 4 calzoncillos lienzo asargado $\ldots \ldots \ldots \ldots \ldots \ldots$ & 40 \\
\hline 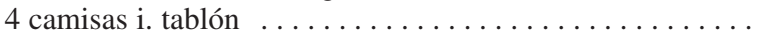 & 36 \\
\hline 1 sombrero de felpa fino $\ldots \ldots \ldots \ldots \ldots \ldots \ldots \ldots$ & 70 \\
\hline 4 pañuelos de algodón a cuadros grandes $\ldots \ldots \ldots \ldots \ldots$ & 16 \\
\hline 36 botellas de vino carlón $\ldots \ldots \ldots \ldots \ldots \ldots \ldots$ & 90 \\
\hline 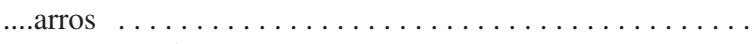 & 8 \\
\hline$\ldots \ldots \ldots \ldots \ldots \ldots \ldots \ldots \ldots$ & 60 \\
\hline arrobas yerba paraguaya $\ldots \ldots \ldots \ldots \ldots \ldots \ldots$ & 300 \\
\hline
\end{tabular}

8 Ante el fracaso de las operaciones confiadas a las Divisiones Derecha y Centro, el General Quiroga, como director de la guerra, resolvió disolver los contingentes, dando término a su breve actuación. Con ello, virtualmente la campaña al desierto quedó concretada a las operaciones que realizaría la División Izquierda (al mando de Rosas), asumiendo éste de hecho la dirección de las operaciones. Walther, Juan Carlos: La conquista del desierto. Síntesis histórica de los principales sucesos ocurridos y operaciones militares realizadas en la pampa y patagonia, contra los indios (años 1527-1885), Tomo I, Círculo Militar, Biblioteca del Oficial, Buenos Aires, 2 de setiembre de 1947.

9 Walther: La conquista ..., pág. 272.

10 González, Miguel Ángel: Catrie Mapu. Monografía sobre los Catriel, Museo Etnográfico de Olavarría, 1967.

11 Archivo Histórico de Azul (en adelante AHA), Legajo año 1840.

12 AHA, Legajo n. ${ }^{\circ}$ 22, año 1845. 
Poco tiempo después se agregan ollas y pavas de hierro, pliegos de papel, baldes...entre otras cosas. ${ }^{13}$ Cuando en 1852 cae el gobierno de Rosas y las nuevas autoridades están dispuestas a cambiar su política con los indios, las tribus de Catriel y Cachul que acampaban entonces a pocas leguas de Azul hicieron notar nuevamente su presencia étnica ${ }^{14}$. Juan 'el viejo' había fallecido en 1848. La crónica nos muestra que ese año, muy enfermo, pide permiso para bajar al fuerte Azul para saludar al comandante. Su hijo, también llamado Juan, hereda el poder, incluido los favores del gobierno porteño. Pero los tiempos han cambiado y el 'compadre' Juan Manuel de Rosas está ahora muy lejos de la pampa. Los nuevos mandatarios no son, en principio, partidarios de hacer alianzas con los indios. Éstos, decepcionados, se alzan en rebeldía y Calfucurá los reúne en lo que se conoció como una verdadera Confederación de Tribus. Algunos malones importantes, entre los que se destaca el de Tandil de 1855 y un par de derrotas sufridas por el general Mitre, llevaron las cosas a su cauce. El mismo Mitre, encomendado por el gobierno porteño, logra renegociar la paz con Catriel. El Estado se obligaba a pasarles trimestralmente a Catriel y Cachul los siguientes artículos:

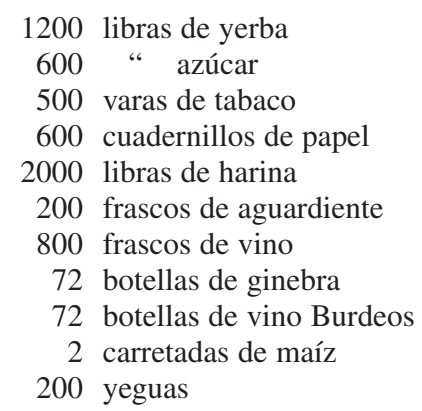

Pero quizá lo más importante resida en su artículo $6 .^{\circ}$, donde consta que se le concede el título de General y Cacique Superior de las tribus del Sud y el uso de charreteras de coronel (a parte de uniforme militar y suel-

13 AHA, Legajo n. ${ }^{\circ}$ 114, año 1847.

14 "En 1855, el gobierno de la provincia de Buenos Aires, entonces separada de la Confederación Argentina, decidió actuar vigorosamente. [Se le confió el mando a]...don Bartolomé Mitre, a la sazón coronel y ministro de guerra... al pie de una colina medianamente elevada que se percibe claramente desde el Azul, se dejó sorprender y rodear por las fuerzas reunidas de los caciques Catriel y Cachul; le quitaron los caballos y lo hostigaron de tal modo que la infortunada columna debió regresar a pie hasta el Azul..." Ebelot, Alfredo: Relatos de la frontera, Ed. Solar-Hachette, Buenos Aires, 1968, pág. 32. 
do) a don Juan Catriel. ${ }^{15}$ Los sueldos destinados al Azul en 1860, y dentro de ellos los de algunos indios, eran los siguientes:

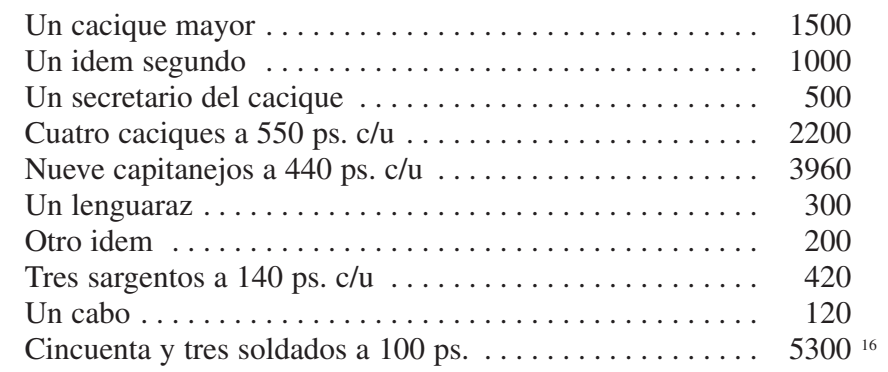

Para tener una referencia sobre los sueldos en cuestión —obtenidos de la misma fuente-, digamos que el Coronel Comandante Militar de la Guarnición de Patagones cobraba 2.420 pesos y que un sargento mayor cobraba 1.190 pesos mientras que un capitán sólo 880 pesos. Observando las dos listas de raciones, y sobre todo los momentos en que se entregan, podemos notar tanto diferencias cualitativas como cuantitativas. En la primera no sólo predominan los regalos para Catriel sino que no aparecen, al menos contabilizados, artículos para la gente de su tribu. Parece claro que esa ración iba destinada al Cacique y en el mejor de los casos a la elite que lo rodeaba. Pero en la ración posterior a Rosas la mayor parte de los artículos van destinados a un consumo masivo que excede el de un grupo privilegiado. ¿Qué cambió entre ambas fechas? Podríamos pensar que en la primera lo étnico, y un espacio de subsistencia mayor, ganado, pesca, boleadas alcanzaban para mantener alejados de los malones a los lanceros amigos. También que en el segundo momento los altos mandos indígenas tuvieran un mayor acceso al circuito metálico (de allí los sueldos que vimos anteriormente) y al consumo directo de sus vicios, al mismo tiempo que el espacio de subsistencia se cercaba y ahora Catriel debía negociar una ración mayormente pensada para su clientela. Por último, la secesión de Buenos Aires y el enfrentamiento con Urquiza exigían destinar toda la energía al norte bonaerense y no al sur. La nueva coyuntura seguía beneficiando a la familia Catriel; Juan, dedicado a la política y sus hijos, Cipriano y Juan José, progresando en el negocio ganadero.

15 Muñiz: Los indios..., págs. 175-176.

16 Registro Estadístico de Buenos Aires, año 1860,tomo I, Imprenta Argentina de El Nacional, 1861, pág. 138 . 


\section{MARCELINO IRIANNI}

Aquel nombramiento de General debió constituir un verdadero punto de inflexión en la vida de Juan Catriel; al mismo tiempo debió confundir fuertemente los sentimientos de lealtad de sus seguidores y de las otras parcialidades. Se trataba de un paso decisivo que delataba sus ambiciones cada vez menos étnicas, y a la vez lo ubicaban en un sitio peligroso frente a los suyos. Adoptaba, ni más ni menos, que la indumentaria del enemigo. ¿Debía justificarlo? ¿O lo poco que aún perduraba de su rol como cacique le permitía estos virajes culturales sin alterar su poder? Acaso la preocupación y justificación, si pensamos en las relaciones clientelísticas, no debía posicionarse con sus lanceros sino frente a sus jefes subalternos y otros caciques amigos.

Llegados hasta aquí, dos cosas parecen quedar claras: en primer lugar, la política de Rosas no debilitó ni la posición étnica de los caciques amigos entre los suyos ni su estructura militar. Se podría pensar que las raciones y el aquietamiento en un sitio que les exigía el gobierno impedirían la reproducción de los lanceros a la vez que fomentarían el relajamiento de sus prácticas bélicas. Parece claro que los caciques supieron mantener, de alguna manera, esa potencialidad como reaseguro a sus riesgosas negociaciones. En segundo término, se sucedieron cambios al interior de esa estructura a tal punto que ahora su líder no sólo podía abandonar físicamente la tribu, sino que podía ir más allá adoptando símbolos del blanco sin que ello (aparentemente) debilitara su posición étnica. ${ }^{17}$

"De tal modo, en la frontera sur nada se descuidó para hacer del cacique Catriel una especie de personaje, oficialmente revestido con las insignias de un general de la nación... Al convertirse en general argentino había adquirido algunas ideas progresistas. Así pues, en lugar de emborracharse con aguardiente se emborrachaba con cerveza. Se hizo construir una casa de tres piezas, con paredes de adobe, piso de tierra apisonada y techo de cinc, la cual entre los suyos pasaba por un palacio."18 Ebelot describe la situación en los siguientes términos: "Desde el fondo de esta mansión temida, lo dirigía todo en la tribu, con precisión facilitada por el miedo que inspiraban sus procedimientos de justicia expeditiva". Por lo demás, si bien

17 En realidad, nada impide pensar que los indios tuvieran la misma inclinación a tomar aquellos elementos, pero menos oportunidades de hacerlo. Aunque no es frecuente, en algunas pinturas o descripciones de los lanceros, no resulta extraño encontrarse con la utilización de sables, quepis o instrumentos propios de los blancos en manos de indios comunes, posiblemente tomados en alguna batalla o asalto. De no ser así, estaríamos suponiendo una actitud cultural purista de los indios comunes, frente a una elite dispuesta al cambio, lo que es teóricamente insostenible.

18 Ebelot: Relatos de ..., pág. 34. 
prohibió el robo en grande y a mano armada, dejaba amplio margen para el merodeo nocturno, que en detalle servía al mismo fin. ..Si alguien se presentaba ante el cacique y se quejaba de una bien probada fechoría de un hombre suyo, sorprendido por casualidad en flagrante delito, el quejoso recibía invariablemente la misma respuesta:

\section{- Hermano ¿por qué no lo mataste como a un perro? ${ }^{19}$}

¿Es representativo el caso catrielero respecto del resto de los caciques de la zona? No quedan dudas de que los indios pampeanos no eran —más allá de que en alguna oportunidad intentaran una coalición - una unidad homogénea y compacta. Podríamos incluso hablar de etnias distintas y los efectos de la araucanización. Pero en vista de lo que queremos desarrollar aquí, no pretendemos avanzar más allá de la macrodivisión indios amigos/indios enemigos. Según Silvia Ratto, estas parcialidades amistosas pueden diferenciarse, oportunamente, aun en dos subgrupos: indígenas aliados e indígenas amigos. Los primeros serían aquellos que mantenían su hábitat en la pampa y esporádicamente obtenían auxilios del gobierno y los segundos aquellos que se habían instalado dentro de la frontera y mantenían una relación más estrecha con el gobierno, por la cual recibían raciones. ${ }^{20}$ Esto resulta de suma importancia en nuestro caso, dado que la primera mutación de los catrieleros parece ser el paso gradual por ambos subgrupos.

Ahora bien, ¿qué sucedía en el interior del mundo de los indios amigos? ¿Cómo funcionaba esa maquinaria compleja que implicaba miles de personas llevada a cabo por la negociación de dos partes, que terminan siendo al fin y al cabo sólo dos individuos? En definitiva, nos estamos preguntando ¿cómo logra lo económico imponerse a lo étnico, lo religioso e incluso lo político que debió prevalecer anteriormente entre estos grupos aborígenes? Y lo que es más interesante, ¿qué efectos trae este cambio al interior de la tribu?

Podríamos adelantar ${ }^{21}$ que el vínculo que mantiene los lazos de verticalidad y lealtad entre los indios (excluyendo a los capitanejos y caciquillos) y Catriel tienen distinto grosor, término gráfico al sólo efecto de una ilusión analítica. Los niveles políticos y social son incuestionables. El nivel

19 Ibídem, pág. 35.

20 Ratto: "El negocio pacífico...".

21 Tema complejo en el que estamos trabajando para una futura ponencia. 
económico es acaso el que define en último término la peligrosidad de la relación. Catriel sabe que si los abastecimientos o un malón oportuno compensan la ración tradicional, la fidelidad está asegurada. El nivel religioso es acaso el más traumático, al menos si entendemos que es allí donde Catriel parece poner toda su energía en el mantenimiento de cierto aislamiento con el mundo blanco. Cipriano, ante la embestida y continuas visitas de los misioneros, ofrece evangelizar a dos de sus hijos, pero deja clara la idea de que no lo harán con sus indios.

Sin embargo, el grosor de los lazos con respecto a los capitanejos y caciquillos es bien distinto. Allí, los cambios en lo económico y lo político deben justificar el viraje beneficiando, o al menos no perjudicando mayormente, a los segundones de Catriel. Los pedidos especiales para aquéllos en cada carta a las autoridades parecen probarlo. Los caciques debían mantenerse en un ajustado equilibrio entre sus pertenencias, sus negocios y las relaciones con los pilares de su poder: los capitanejos y caciquillos. "En mayo de 1871 los caciques Manuel Grande, Calfuquil y Chipitruz que obedecían a Catriel, con el pretexto de demorarles la entrega de los sueldos y raciones se sublevaron contra este cacique, obligando al coronel de Elías [comandante de la frontera sur] a atacarlos de inmediato para conjurar ese peligro, resultando muertos los cabecillas. Ocurrió que Catriel, al ver minada su autoridad, en virtud de los tratados firmados, dio cuenta al jefe de la frontera de la actitud de sus subordinados motivando la intervención armada del coronel de Elías. Al respecto, el coronel Boer [jefe de la frontera oeste de Buenos Aires] comunicó posteriormente el 8 de mayo a la superioridad, que los caciques Manuel Grande y Chipitruz se presentaron en el sector a su cargo, solicitando amparo porque fueron atacados por el cacique Catriel y parte de las fuerzas de la División del jefe de la frontera sud." ${ }^{22}$ Mientras que lo político y lo económico se presentan ante nuestras miradas como temas más abordables (a menos desde el punto de vista de las fuentes), lo religioso y lo cultural han sido descuidados en aquel nivel de las jefaturas.

Muerto Juan Catriel (h), entre 1866 y 1868, sus hijos Cipriano y luego Juan José deberán emprender todo tipo de negociaciones para acomodarse a una coyuntura que les arrinconaba irreversiblemente. Al principio, Cipriano permaneció fiel a la Comandancia de Frontera del Azul, relacionado con la persona del General Ignacio Rivas. Precisamente, el 5 de mar-

22 Walther: La conquista..., pág. 117. 
zo de 1872, Calfucurá invade al frente de 6.000 indios los partidos de Alvear, 25 de mayo y 9 de julio. Mientras vigilaba con una parte de sus huestes a las tropas de Azul, el resto saqueó los establecimientos y poblaciones, donde se apoderó de 200.000 cabezas de ganado y 500 cautivos y mató a unos 300 pobladores después de incendiar sus viviendas. El jefe de la frontera, general Rivas, avanzó desde Azul al frente de las fuerzas de las fronteras sur y costa sur en protección del coronel Boer. Asimismo, ordenó al cacique amigo Catriel la convergencia hacia ese lugar con su tribu. En total Rivas juntó unos 1800 hombres de los cuales 800 eran indios de Catriel y de Coliqueo. ${ }^{23}$

Cuando llega la década de 1870, Cipriano muestra sus cartas a los capitanejos, los otros caciques y a su gente: está dispuesto a seguir avanzando hacia el mundo de los blancos sin medir las consecuencias. Según el coronel Walter, el general Rivas decidió descansar en San Carlos y esperar el regreso de Calfucurá para atacarlo, ambos adversarios chocaron en la mañana del 8 de marzo a legua y media al noroeste de San Carlos. Los indios, maniobrando al toque del clarín, desplegaron y pasaron al ataque con un furor inusitado, se entablaron un reñido combate, por ambos bandos se hizo gala de coraje y valor, especialmente por parte de los indios de Catriel. En un principio los indios de Catriel y de Coliqueo atacaron débilmente; pero el famoso cacique, ebrio de coraje y de valor, se impuso a los suyos, mandando fusilar a algunos de los más remisos y ya los indios, viéndose atacados por la división de indios chilenos que mandaba Reuqué Curá, recordaron antiguos y adormecidos agravios, entre pampas y araucanos, y confundiendo sus salvajes alaridos con los de sus atacantes, volvieron al combate con tan irresistible ímpetu, que Reuque Curá y los suyos fueron derrotados después de un tenaz entrevero a facón y bola.

Alfredo Ebelot ${ }^{24}$ opina que esta nueva época está signada por una serie de fracasos militares (Mitre y demás), a los que siguen un par de años, hasta la llegada de Alsina, cuyo gobierno pensó que a los indios sólo los podrían vencer otros indios, inaugurando una serie de dones y contradones para entablar alianzas y enemistar las distintas parcialidades. Por último, entrada la década del ' 70 , y en momentos en que los indios amigos participaban incluso de revueltas civiles, Avellaneda, Alsina y Roca decidieron transfor-

23 Ibídem.

24 Ebelot: Relatos de ... 
mar (posiblemente porque la coyuntura internacional así lo requería) la defensiva en una ofensiva final sin precedentes. El hermano del cacique, Juan José, intentará - al visualizar que el espacio blanco se cerraba con los nuevos negociadores que enviaba el gobierno-, luego de una revuelta civil en la que Cipriano se jugó una carta de triunfo y perdió, recuperar el lugar étnico entre los suyos y en la geopolítica pampeana. Como vimos, después de la batalla de San Carlos, en la que las huestes de Calfucurá fueron derrotadas gracias a la intervención de los indios amigos a favor del ejército blanco, la suerte de los catrieleros estaba echada. De allí en más, sólo realizarían pequeñas demostraciones de lealtad para frenar la celeridad de un desenlace largamente temido. Juan José intenta entonces la compleja jugada de terminar de recuperar su etnicidad despojándose de sus amuletos blancos, pero sin perder su patrimonio ganadero.

Entre los militares de la nueva época, Ebelot cita al coronel Nicolás Levalle, que se enemista seriamente con Juan José al mostrar una incómoda tarjeta de presentación. "El coronel quiso asistir a su distribución [de una ración llegada a Azul]. Contó las vacas, midió el aguardiente, pesó el tabaco y, comprobando el déficit, preguntó severamente qué significaba eso. El proveedor exhibió el recibo del cacique. El coronel se apoderó del documento como elemento de prueba y lo envió al ministro de guerra. El incidente fue ruidoso; nada podía ser más desagradable para Catriel. Era su "lista civil" lo que se le confiscaba. Rezongó; los grandes personajes de la tribu rezongaron; pero los capitanejos de último rango y la vil (sic) multitud hallaron algo de bueno en las ideas del coronel. ${ }^{.25}$ Esta cita, más allá de señalarnos el principio del fin, encierra una pista probable a tantos interrogantes vertidos en estas páginas. Lo étnico se relaja y se hace difuso de arriba hacia abajo. El piso de la mutación parecen ser los capitanejos de último rango y los lanceros. Ese piso, tan impermeable como inaccesible al reparto, era quienes lo componían.

El título con que abrimos este apartado es, visto desde aquí, tan engañoso como real. Al mismo tiempo que encierra una imagen relajada y armoniosa de Catriel, lo presenta con términos tan vagos como "amigo de la pampa", frase vacía si las hay. Pero en realidad, ése era el término más adecuado para la clase alta porteña, el gobierno y el ejército, dado que 'amigo' sólo describe una situación coyuntural en una relación, la que puede cambiar, mientras que 'la pampa' alude mayormente al nicho ecológico

25 Ibídem, pág. 40. 
que a la sociedad blanca. Ese conjunto de vaguedades, puramente coyuntural, eludía la posibilidad de otros rótulos como 'Los catrieleros, los indios dueños de la tierra' o 'La gente de Catriel, de lanceros al mercado de trabajo en formación'. Sin embargo, si en algo no se equivoca la frase es en poner el acento de dicho grupo aborigen en la figura de Catriel; personalismo que debemos revisar tanto desde el punto de vista de la relación hacia adentro de la tribu como en los puentes de contacto con la sociedad blanca. ${ }^{26}$ Acaso la unión de dos mundos por medio de un cordón umbilical estaba destinado a congelar la relación entre un grupo de personas, las elites de ambas partes.

\section{Caciques y kurakas. Con 'un pie' en el mundo blanco ${ }^{27}$}

Los aborígenes de distintas partes del mundo sufrieron, desde los siglos XVI al XIX, las consecuencias del poblamiento de los territorios que ocupaban y el avance civilizador. Es posible, a efectos de adelantar un poco en la definición pero sin ánimo de encontrar paralelos exactos, que algunas categorías empleadas para analizar ese fenómeno en distintos puntos de América se conviertan en eficaces mecanismos para efectuar algunas comparaciones. En este caso nos referiremos a kuracas (andinos) y caciques (pampeanos), pero podríamos extender los ejemplos a Gerónimo, Toro Sentado y otros jefes étnicos de Norteamérica. ${ }^{28}$

El primer problema que se nos presenta, a primera vista, es que dicho concepto no se ajusta tan siquiera acabadamente a los distintos casos del territorio pampeano. Catriel y Colliqueo parecen tener poco en común por ejemplo con Calfucurá. Posiblemente lo que nos dificulta observar sus características comunes es cotejar la confederación interétnica que intentó Calfucurá (verdadera jefatura) con los dominios más restringidos de los primeros. Es posible también que la condición de indios amigos de Catriel y Colliqueo debilite a priori nuestro concepto de cacique frente al sobera-

26 Para ampliar sobre el fuerte personalismo que adquieren los tratados con posterioridad a Rosas ver Ratto: Conflicto, poder...

27 "Prefiero morir como buen pampa y no como mal cristiano". Respuesta de Catriel al P. Sánchez labrador que intentaba catequizarlo y atraer a la vida civilizada. En Cuadrado Hernández: "La dinastía de...".

28 Para ampliar sobre los caciques de Norteamérica ver, entre otros, Freeman, Rusell: Los grandes jefes indios, Loguez Ediciones, España, 2002; y Sonnichsen, C. L. (ed.): Jerónimo. El final de las Guerras Apaches, Libergraf, Barcelona, 1993. 
no de Chilihué. ${ }^{29}$ En tal caso, el elemento sustancial que entorpece la comparación es lo étnico. La condición de cacique (como la de kuraka) se vuelve difusa cuando queremos utilizarla para referirnos a un numen que ha adquirido otros cargos o status (general, hacendado) propios de los blancos. Esta sensación también debió estar latente en las parcialidades de aquellos jefes aborígenes; por lo que debió ser crecientemente indispensable contrarrestar la pérdida de lo étnico con elementos otrora ajenos a la sociedad india (vicios, etcétera).

Karen Spalding, refiriéndose al mundo andino, cree que "la incorporación al imperio europeo transformó la sociedad a través de formas más sutiles, modificando y cambiando sus patrones sociales y culturales por la introducción de nuevas limitaciones y restricciones, al igual que de nuevas perspectivas y oportunidades para algunos." ${ }^{{ }^{30}}$ Con recaudos, en la pampa no debió ser muy distinto. Inevitablemente, el espacio indígena pampeano - tanto de los indios rebeldes como de los amistosos - se cercaba con la llegada paulatina de colonos y milicos a distintos puntos de una provincia que se ensancharía hasta los márgenes de las mejores tierras. Las grandes estancias disolvieron rápidamente el espacio de subsistencia del que hablaba Carlos Mayo, ${ }^{31}$ que en definitiva debió funcionar para gauchos alzados, pero también para los indios. Al interior de las tribus, la reciprocidad y la redistribución ${ }^{32}$ que mantenían la lealtad de sus lanzas debieron ser cada vez más ineficientes para sostener el poder del cacique que presionaba $-\mathrm{y}$ apuntalaba - a los gobiernos con su clientela armada. Por otra parte, el aumento de riquezas de Catriel, mediante regalos, apropiación de ganado y sueldos, debió atarle cada vez más a un lugar físico, obligándolo a reproducir los tratados de amistad, a la vez que haciéndole perder definitivamente las posibilidades de recuperar la independencia o alianzas con indios alzados.

Al igual que en el mundo andino, en la pampa húmeda "la conquista española (y luego criolla) introdujo nuevos modelos de obtener riqueza y poder que alteraron sustancialmente la estructura interna de la sociedad india. Una característica principal fue el carácter individual de las oportu-

29 No debemos olvidar que Calfucurá también dejó de lado la etnicidad para emprender negociaciones con Urquiza.

30 Spalding, Karen: De indio a campesino, IEP, Lima, 1979.

31 Para el ampliar sobre el concepto de espacio de subsistencia y las polémicas que trajo consigo, ver, por ejemplo, el número 2 del IEHS, UNICEN, Tandil, 1987.

32 Para ampliar sobre el tema ver Mandrini, Raúl: "Pedir con vuelta. ¿Reciprocidad diferida o mecanismo de poder?, en Antropológicas, Nueva Época, UNAM, México, 1992. 
nidades. Un individuo ambicioso podía obtener la riqueza y el poder independientemente ${ }^{33}$ de su grupo."${ }^{34}$ En los Andes como en la pampa no eran muchos los individuos posicionados favorablemente para este cambio. Sin embargo, algunos kurakas y caciques contaban con una plataforma económica y política — sumada a su pertenencia étnica — interesante para experimentarlo.

Steve Stern, por su parte, advierte sobre el objetivo final de la mercantilización cacical, preguntándose si ésta significa una adopción e incorporación de pautas europeas (enriquecimiento individual) o si ese barniz mercantil apunta al mantenimiento de pautas tradicionales traducidas en la reversión de ganancias para la comunidad frente a problemas climáticos y de cosecha o para realizar rituales y fiestas. Ha encontrado, en este sentido, un modo de comportamiento indígena colonial (reciprocidad, redistribución, autosuficiencia) junto al eficiente aprovechamiento de las oportunidades mercantiles. ${ }^{35}$ ¿Por qué no pensar, llegados hasta aquí, que la transformación de Catriel lejos de presentarse como una mala estrategia, era la única posible? No caben dudas de que era finita y entraba en un inevitable cuello de botella, dado que mientras que él se enriquecía individualmente (familiarmente) se achicaba el territorio otrora dominado por su etnia y por ende aumentaba la precariedad y pobreza del conjunto. Mientras tanto, sus aliados de turno avanzaban, poblaban, se tecnificaban y necesitaban en forma decreciente de sus servicios. Posiblemente Catriel visualizaba ese destino trágico de su tribu pero también un final más feliz para un servidor sin reparos como él.

Tanto los españoles en el siglo XVIII como Rosas en el XIX permitieron la configuración de nuevos canales de movilidad social, estratégicos en sus expectativas de dominación territorial y que, aunque claros para el elemento aborigen interesado, aparecían más difusos y sin entorpecer a la elite criolla porteña. Lo más importante, según Spalding, es el poder que estos individuos esgrimían sobre los suyos amparados por el gobierno español; incluso podían burlar o ignorar sanciones tradicionales andinas. ${ }^{36}$

33 En realidad, diferimos en este punto con Spalding, dado que precisamente lo que les permite a Kurakas y caciques obtener riquezas es su clientela étnica. Sin ella tendrían poco margen para negociar. Sí es cierto que las relaciones personales y las redes, aunque apoyadas en la presencia de la comunidad que lo sostiene, son ahora individuales, ver Spalding: De indio a...

34 Ibídem. La cursiva es nuestra.

35 Stern, Steve: Los pueblos indígenas del Perú y el desafío de la conquista española, Alianza, Madrid, 1986.

36 Spalding: De indio a... 
Como vimos, Catriel y sus allegados incorporarán, en este mismo sentido, prácticas, comportamientos y hasta vestimentas extrañas a su cultura. Ebelot rescata, entre sus narraciones, el relato de la viuda de Railef, capitanejo de Catriel:

"Desde que lo vi me enamoré de él. Ustedes saben como era de vivo, alegre, atrevido, presumido en el arreglo, lo bien que jugaba al billar y cuanto le gustaban la manera de vivir y los placeres de los cristianos". ${ }^{37}$

Pero acaso Cipriano fue el más progresista, sinónimo de arriesgado en nuestra línea de análisis.

"En su tren europeizante, Cipriano no para en mientes. Adquiere un lujoso carruaje con el que recorre las polvorientas calles del Azul y utiliza en sus marchas. Y hasta posee cuenta bancaria, una marca para su hacienda, su sastre y su sombrero. ${ }^{38}$

Algunas referencias del comportamiento de aquellos caciques muestran, de todos modos, que entre ambos mundos había zonas grises donde se podían satisfacer las ambiciones personales y atracciones del mundo blanco sin afectar dramáticamente el perfil aborigen ante la tribu. Armaignac, que visitara a Cipriano Catriel en 1868, relata dos situaciones que reflejan ese lugar donde se movían los caciques para preservar el equilibrio.

"Seguimos nuestro camino, y poco después estábamos ante la habitación de Catriel. El rancho era de un aspecto muy mediocre, constaba de una sola habitación que servía de dormitorio y, en ese momento de salón. Se componía simplemente de un techo de paja en forma de libro abierto o de tienda militar que se apoyaba en el suelo, cuyo nivel había sido elevado algunas pulgadas en aquel lugar. Las partes triangulares de ambas extremidades estaban cerradas por una empalizada de chorizo, provisto de una puerta de tablones. Este cuarto mediría aproximadamente tres metros de altura en su parte central, y cuatro metros de largo por tres de ancho. Todo el moblaje consistía en algunas pieles de oveja y algunos malos pedazos de alfombra o de mantas que servían de día para sentarse y de noche para acostarse. Bridas, riendas, un freno de plata y algunos otros aperos colgaban de la pared del fondo, cuya principal decoración consistía en una mala trompeta de cobre, toda abollada, y un gran sable con empuñadura y vaina de plata, que Catriel había heredado de su padre y lucía en las grandes ocasiones. Para darnos el ejemplo, el jefe se sentó en cuclillas en el extremo del cuarto y nos invitó a imitarlo. ${ }^{39}$

\footnotetext{
37 Ebelot: Relatos de...

38 Ibídem, pág. 42.

39 Armaignac, H.: Viajes por las pampas argentinas. Cacerías en el Quequén Grande, Eudeba, Buenos Aires, 1976., págs. 122-123.
} 
Habitar un rancho en vez de un toldo, pero sin muebles y sentándose en el suelo, era una manera simple de estar a mitad de camino. Pero si en algún aspecto se denota con mayor claridad esa posibilidad de cabalgar entre los dos mundos, es acaso en el idiomático.

Después del festín, mientras el lenguaraz estaba jugando con los chicos, Catriel me dijo, en bastante mal español, que lo siguiera. Ambos nos dirigimos hacia un arroyuelo que corría a doscientos o trescientos metros de allí, y emprendimos una larga conversación. Delante de todos, el cacique fingía ignorar el español y, aunque hablara sin tropiezos esa lengua, se hacía traducir mis respuestas al idioma pampa cuando Avendaño o alguna otra persona estaban presentes. Durante ese paseo me hizo muchas preguntas sobre mi país; me habló de la guerra franco-prusiana...Me pidió informes sobre el mar y los barcos que no conocía... ${ }^{40}$

Los caciques podían disimular o no su atracción hacia aspectos culturales del blanco, pero lo que definitivamente no podían esconder era el aumento de sus pertenencias personales y riqueza. Tan evidente es también el rol de hacendado de Juan José Catriel en la década de 1870, que aún siendo el heredero natural cuando muere su padre Juan, no toma el cargo porque "quería dedicarse a la hacienda numerosa que poseía" ${ }^{41}$ La pregunta es ¿cómo se acomodaba la pobreza creciente de su gente con la cada vez menos inocultable riqueza personal? ¿Aumento de la represión hacia el interior de la tribu? ¿Apertura a un número mayor de indios a la elite que gozaba de los beneficios? Ya hemos visto con su padre la vista gorda a algunas salidas a bolear y maloquear, ${ }^{42}$ lo mismo que las raciones (en las que el alcohol y el tabaco predominaban) permitían estas transformaciones. No debemos olvidar que la tribu era una especie de racimo, unido por un tallo común pero fragmentado en distintos gajos menores (los capitanejos) que eran los verdaderos sostenedores del conjunto.

Entonces, ¿por qué se quiebra el nuevo orden impuesto en el territorio pampeano donde algunos caciques pudieron acceder a instalarse social y hasta culturalmente junto a los criollos? Sucede que estos nuevos canales de movilidad social no se mantuvieron abiertos durante toda la época colonial en los Andes ni durante todo el siglo XIX en el Río de la Plata. En el Altiplano comenzó a restringirse, alrededor del 1700, al mismo tiempo que

40 Ibídem, pág. 123 pág. 223.

41 Declaración de la viuda de Juan José en 1923 a Del Valle. Del Valle: Recordando...,

42 Mientras que bolear significa permitirles salir a cazar ñandúes u otros animales (prohibido por ley) para palear el hambre, maloquear refiere a robar algún animal de una propiedad. 
declinaba la economía colonial. Los españoles exigían más a esos privilegiados que no lograban conformarlos y ahora los usaban mayormente para expoliar a la masa. ${ }^{43} \mathrm{El}$ paralelo pampeano, dado que aquí no se cobraba tributo a los aborígenes, era una mayor exigencia de participación bélica en asuntos políticos que poco tenían que ver con la problemática aborigen desde mitades del XIX.

Ahora bien, ¿por qué Catriel, al igual que Tupac Amaru, no terminaron de traspasar la línea hacia el mundo blanco? Un indio vestido como un español y aprendiendo esa lengua pasaba - dice Spalding - desapercibido. Pero ambas sociedades estaban articuladas en torno a los lazos de parentesco, reales o ficticios, que proporcionaban la única seguridad de pureza. 'Disfrazados' y solos (fuera de las redes necesarias e imprescindibles), ninguno de los dos tenía posibilidades de prestigio. Un indio noble no negaría su ancestro, inclusive porque mucho de su prestigio y riqueza se lo debía a ellos. Más aún, siendo nobles sentían el desprecio español, o criollo, y algunos decidían retornar a su lugar tradicional, como orgullo y auto respeto. Es posible que al final de sus días Cipriano Catriel o su hermano Juan José recordaran con tristeza la frase de su padre que abre este apartado. Era, claro está, demasiado tarde para regresar a la senda que habían seguido inalterablemente sus antepasados hasta que el viejo Juan Catriel decidiera tomar el atajo que llevaba a las 'ventajas' de la amistad con el blanco.

Hacia 1875 el gobierno decide, coincidiendo con la muerte de Cipriano y el nuevo liderazgo de Juan José, trasladar a los catrieleros a nuevas tierras. La razón obedecía tanto a las quejas de muchos vecinos cansados de los robos como al entusiasmo de algunos inversores deseosos de adquirir posiblemente las mejores tierras de la provincia. Sin embargo, otros tantos personajes de la frontera hicieron saber sobre su descontento por esta expulsión. Ebelot recuerda cómo "los pulperos vieron con amargura esfumárseles la magnífica clientela de casi dos mil bebedores... Los gallegos, ${ }^{44}$ desconcertados un momento por lo imprevisto del golpe, liquidaron sus existencias de cueros, cerraron sus maletas y se aprestaron a seguir en el éxodo a sus buenos amigos de la tribu". ${ }^{45}$ Estas diferencias de opinión respecto de los indios amigos son un claro indicio de que aquéllos no presentaban un problema gravísimo para la sociedad blanca azuleña.

43 Spalding: De indio a...

44 Término con que se engloba a la colectividad española, aunque refiera con una mirada más estrecha a los provenientes de Galicia, mayormente dedicados al comercio.

45 Ebelot: Relatos..., pág. 45. 
Pero posiblemente lo más interesante de la situación es que Alsina había convocado a un Parlamento a los líderes indios, mientras Ebelot y los ingenieros trabajaban sin demoras para proponerles el reparto de tierras en el nuevo destino. La oferta consistía en una "estancia de una legua cuadrada para el cacique; chacras de 170 hectáreas para los jefes secundarios y quintas de 35 para los simples lanzas... El establecimiento proyectado, sin precedentes, era a la vez un asiento militar destinado a la vigilancia de la frontera pero necesitado él mismo de activa fiscalización, y también una colonia pastoril y agrícola, y por último germen de una ciudad." ${ }^{* 46}$

Más allá de que este proyecto no prosperara, podemos rescatar el hecho de que el gobierno le ofrecía un trato a los indios que consideraban factible. Esto es lo relevante, el conocimiento que aquellos comandantes y políticos tenían de los catrieleros les animó a ofrecerles la posibilidad de convertirlos en terratenientes y chacareros. El revés del resultado no invalida la poca distancia que separaba a ambos grupos en ese momento. Todo parecía indicar que lo económico y social había aniquilado el elemento étnico. Si su gente había 'aceptado' (seguramente después de un prolongadísimo discurso de Catriel) lo beneficioso del asentamiento permanente y la conversión a productores minifundistas, todo hace pensar que aquéllos ya no se conformaban con las migajas del acuerdo entre los blancos y su cacique (alcohol, tabaco y poco más). Pero como dijimos a lo largo del trabajo, éste es el punto de llegada de un desvío que peligrosamente tomó el propio Catriel cuando aceptó pasar más allá de la línea alejándose del equilibrio entre sus tradiciones y lo nuevo.

El relato de Ebelot sobre la llegada de los parlamentarios indígenas es patético e ilustra el momento en que se hallaba la transformación de uno de los últimos catrieleros a la que aludimos en el título de este trabajo.

"Catriel llegó seguido de un Estado mayor heterogéneo... A caballo, todo ese mundo presentaba cierta buena traza. Manejaban con soltura hermosas bestias enjaezadas de plata. A pie, eran otros hombres. Sus piernas arqueadas, sus hombros redondos, su andar desmañado, entorpecido además por espuelas de grandes rodajas arrastradas por el suelo con un ruido de chatarra.

El cacique y varios de sus capitanejos estaban vestidos con el severo y pintoresco traje de los hombres de campo acomodados: botas blandas, espuelas de plata, bombachas negras y el poncho flotante sobre los hombros; otros estaban cubiertos con repulsivos andrajos, y todos uniformemente calzados con botas de potro." ${ }^{47}$

46 Ibídem, pág. 46.

47 Ibídem. 
La historia tiene un desenlace tan rápido y súbito como lo fue su comienzo. Así como Catriel 'el Viejo' se encontró de la noche a la mañana en una posición de poder inimaginada, su bisnieto vio desmoronarse en un instante el castillo de naipes que había construido durante medio siglo. El Gobierno no los necesitaba más. El 25 de diciembre de 1875, Catriel une sus fuerzas a Namuncurá y lleva a cabo una de las invasiones más impresionantes de la Historia. Por su parte Pincén y Baigorrita hicieron lo suyo por los pagos de la Blanca Grande y Tapalqué.

\section{¿Cacique, general, caudillo y hacendado?}

Ahora que conocemos el final de la gente, volvamos sobre los personajes y roles que los acompañaron durante el fenómeno analizado. A primera vista, todo parece indicar que existe alguna contradicción en el título de este apartado. Nuestros conocimientos de los sucesos históricos bonaerenses se confunden al querer comprender categorías o roles tan antagónicos. Sin embargo, aunque con denodados esfuerzos, Juan Catriel (h) pudo llevarlos a la práctica. Parece claro que él o su sucesor Cipriano — como otros caciques- se convierten al final de sus días en hacendados y su gente se presenta como una verdadera clientela.

Si volvemos nuestra mirada una vez más al subtítulo de este apartado, podemos pensar que en la medida que se afianzaba uno de esos roles se debilitaba inevitablemente otro. El ejemplo más claro es quizá el de general avanzando sobre el de cacique; aunque el de hacendado sobre el de aquel cacique que maloqueaba ganado 'ajeno' no es menos contundente. En la medida en que un cacique intentara preservar parte de lo obtenido en el malón para su patrimonio se resentiría notablemente el circuito económico del que nos hablara Raúl Mandrini ${ }^{48}$ y, lo que es peor, todos sus efectos cohesionantes. Todo parece indicar que los dos circuitos complementarios (el del malón y el de la toldería) no eran teóricamente compatibles con los caciques amistosos. Es probable que los caciques amigos abandonaran su antigua independencia para ocupar el nuevo rol, luego de evaluar las posibilidades reales que tenían de maloquear cotejando sus fuerzas con las de otros caciques como por ejemplo Yanketruz, Pincén o Calfucurá.

48 Mandrini, Raúl: "La sociedad indígena de las pampas en el siglo XIX", en Lischetti, Mirta (comp.): Antropología, Eudeba, Buenos Aires, 1985, pág. 209 y ss. 
Aquellos poderosos adueñados de las rastrilladas y ubicados geográficamente en puntos menos vulnerables - por el momento- que Catriel o Colliqueo tenían demasiadas cartas para aceptar socios igualitarios en la empresa. Nos preguntamos nuevamente, ¿acaso convertirse en cacique amistoso no era la mejor salida para Catriel? No olvidemos que en muchas oportunidades ( entre 1850 y principios de 1870) éstos se vieron acosados por los caciques mencionados. Si nuestra línea argumental es correcta, entre las parcialidades amistosas el aprovisionamiento trimestral bien pudo reemplazar el circuito del malón y complementar (aunque en forma más deficiente que el malón) el de las tolderías.

De todos modos, dijimos que la decisión de Catriel tenía en sí misma el germen de su propia destrucción. Ebelot nos brinda una pista que puede resultar interesante. Surge cuando él se pregunta por qué Catriel u otros caciques no tomaban decisiones de castigar a su gente cuando un blanco se quejaba de algún robo o infracción claramente realizada por los indios a su cargo. "Había otro motivo — comenta Ebelot— poco confesable y por consiguiente decisivo. La tribu se alimentaba a costa del Estado, pero las distribuciones de víveres secos y ganados en pie no eran diarias; se efectuaban a intervalos irregulares, según el hábito de desorden caro a la administración pública argentina. Gracias a misteriosos tratos con el proveedor, el cacique recibía en especies solamente una cuarta o quinta parte de las raciones y daba quitanza del total a cambio de una renta en dinero que le servía para sostener su boato. La tribu, pues, para subsistir durante tres meses no tenía más que las provisiones que, economizadas, habrían podido mantenerlas tres semanas. Como la previsión no es cualidad predominante en los salvajes, éstos se veían a los ocho días frente a la alternativa de morirse de hambre o ponerse a cazar bienes ajenos." ${ }^{49}$

Ese diferencial a favor del cacique era un arma de doble filo. Le acercaba a la elite blanca (proveedores, comerciantes y generalato) pero le minaba lenta pero irreversiblemente su base étnica. Si aquélla se desarmaba, no habría más lanzas, no más raciones, no más diferencial ni sueldo de general. Todo ello sin olvidar que, como concluye Silvia Ratto, las raciones en la economía de las tribus representaron sólo un complemento de lo necesario para vivir. Y más que significar una ayuda global para toda la tribu, terminaron siendo una vía de enriquecimiento de algunos pocos..$^{50}$

49 Ibídem, págs. 35-36.

50 Ratto: "El negocio pacífico...". 


\section{MARCELINO IRIANNI}

Hemos visto a lo largo del trabajo indicios de que tanto Catriel como sus hijos Cipriano y Juan José llegaron a concentrar equilibradamente sus roles de caciques, generales, caudillos y hacendados. En realidad, vistos con detenimiento, algunos de ellos tienen más elementos en común que diferencias. La diferencia entre ser cacique, general o caudillo es más bien étnica y en su interior, cada uno de estos roles se apoya en la base de un liderazgo conseguido en forma natural o no. De todos modos, si un general lo consigue por mandato y no sabe mantenerlo no logrará éxitos ni siquiera mayor duración en el cargo. Lo más notable sigue siendo la aceptación del cargo de general no sólo por parte del cacique sino de quienes lo seguían. Esto debió ser posible por la extensión hacia abajo de rangos similares de capitanejos y sargentos, personajes importantes que apuntalaban el poder del cacique con sus respectivas clientelas de lanceros e indios pobres. Pero también porque la supremacía del cacique (ancestral pero también mantenida sobre la base de la redistribución) le mantenían como incuestionable.

\footnotetext{
"Hacia las cinco, nuevamente resonó la trompeta. Las mujeres se retiraron a sus toldos y todos los hombres montaron a caballo y fueron en busca de sus lanzas. Cuando estuvieron montados y armados, se formaron en escuadrones fuera del campamento, cada uno bajo el mando de un caciquillo o de un capitanejo. Delante de todo el ejército iban los dos caballos sagrados montados por sus guardianes. Inmediatamente, venía el cacique en un soberbio caballo que había merecido el carácter de sagrado el año anterior. Era un espectáculo realmente imponente ver reunidos a todos esos indios de rostro salvaje, empuñando sus largas lanzas y montando caballos recubiertos enteramente de plata, cuando sus jinetes iban semidesnudos o vestidos de sórdidos andrajos. Catriel llevaba en la mano su gran sable con empuñadura y vaina de plata. Vestía chiripá amarillo y cubría sus hombros un poncho azul con cruces blancas. Llevaba un flamante quepís de general, que contrastaba de manera singular con el resto de su vestimenta. Algunos de los jefes subalternos usaban también quepís, pero viejos y de todos colores, cuando no chambergos, y en la mano un sable herrumbrado." ${ }_{51}$
}

Más difícil de explicar resulta sin duda el rol de hacendado. Es evidente que éste no fue un movimiento inesperado sino más bien una transformación económica que comenzó con el asentamiento más o menos definitivo y el plus acumulativo que le dejaban, por un lado, los malones y, por otro, las raciones distribuidas en forma antojadiza. Entre sus pares de otras regiones el temario de conversación era similar al que podían tener dos hacendados bonaerenses.

51 Armaignac: Viaje por... pág. 129. 
"Entonces el cacique se sentó en su trono. Los notables de la tribu empezaron a llegar. Cada uno se acercaba a dar la mano a Catriel, le dirigía algunas palabras, e iba a sentarse... Avendaño me dijo más tarde que se trataba de una especie de saludo: 'Buenos días, jefe. Tu respetuoso y abnegado servidor te presenta sus homenajes; te desea buena salud y te pregunta si no ha sucedido nada malo en tu familia y en tus ganados'. El cacique contestaba: 'Buenos días, fulano. Yo te agradezco tus deseos y espero que tengas mucha prosperidad y felicidad con tu familia y tus ganados". ${ }^{52}$

Como puede verse, más allá de que fuera un saludo y no una conversación prolongada, lo principal en un encuentro de aquellos caciques giraba en torno al Estado de la familia cercana del cacique y seguidamente el patrimonio. Si cualitativamente la comparación no es desacertada, la cantidad de ganado en sus manos no distaba de la que podía tener uno de los hacendados en cuestión. Cuando Ebelot relata la invasión de 1875 que le pilló en el fortín Aldecoa, agrega una nueva pista de la dimensión pastoril de Juan José.

"A eso de las diez, una nube de polvo nos anunció que la invasión llegaba. Pronto se distinguió el mugido de los vacunos, y cosa más inquietante, el balido de las ovejas. [Catriel] venía pues arriando sus propias ovejas y todas las que encontró en el camino. Serían unas treinta mil... Durante cuatro horas vimos sucederse las selvas de lanzas y las inmensas tropas de vacas y de caballos. Había por lo menos 150.000 cabezas de ganado". ${ }^{3}$

No podemos cerrar estas páginas sin intentar entender por qué Juan José Catriel rechazó la oferta de una estancia de una legua cuadrada en donde instalar su hacienda. ¿Premonición de que aquel proyecto era inviable para continuar en su camino económico y socialmente ascendente? ¿Qué proyección realizó sobre su clientela étnica desperdigada e inoperable en chacras que rodeaban su estancia?

\section{Conclusiones}

Juan Catriel 'el Viejo' inició hacia 1820 un proceso metamorfósico que lo involucraba a él y su descendencia. En parte consciente y en parte no pergeñada, aquel cacique pampeano fue mutando su rol por otros que se constituían a veces como aparentemente complementarios y otras veces

52 Ibídem, pág. 128.

53 Ebelot: Relatos de..., págs. 61-63. 
antagónicos. Empero, los nuevos roles ensayados por Catriel para acomodarse a coyunturas tan cambiantes como la provincia de Buenos Aires y sus gobiernos se nutrían de la esencia del cacique, pero también en desmedro de aquél. Si no fuese así, la metáfora de la metamorfosis no sería apropiada, toda vez que en dicho proceso hay cambio de formas que aprovechan parte de lo viejo agregando elementos nuevos a la figura.

Respecto del rol de hacendado, todo parece indicar que fue quizá la parte más natural de la transformación. Cuando media el siglo XIX, hacía mucho tiempo que el poder de los caciques se sustentaba de una u otra forma en el ganado. No podemos concebir que Catriel se convirtiese en hacendado si no fuese cacique; como tal tenía los medios para hacerlo. De ser virtualmente el dueño (al menos era él quien disponía los resultantes del negocio) de un arreo de varios miles de cabezas de ganado hasta Chile a poseer ese ganado pastando en una región más o menos circunscripta había unos pocos pasos. No eran fáciles, sobre todo teniendo en cuenta lo que ocasionaba a su gente: desmovilización, semisedentarismo, etcétera; pero tampoco imposibles, porque había cierto consenso de parte del generalato y por ende de varios sectores del mundo blanco ligados a esa producción.

El rol de general se presenta, a priori, casi como un potenciador sustancial de los atributos del cacique, aunque también debe verse como un escalón sólo accesible desde aquella posición étnica. El Estado ganaba tiempo manteniendo aliado a un potencial enemigo incorporándolo al sistema en un cargo tan efímero como simbólico. A medida que el cacique reconcentraba, como una estrategia de subsistencia, el poder mutar parte de su figura de cacique hacia un rol en apariencia más poderoso, desde el universo de su gente como totalidad a la decena de caciquillos y segundos que lo apuntalaban, era aceptable. Fuera de su círculo de poder, el resto de la gente de la tribu, atomizada en órbitas junto a cada caciquillo, no tenía opinión ni medios para impedirlo.

A medida que avanzaba el siglo XIX, el cacique se desdibujaba hacia afuera y también hacia adentro, acrecentándose la figura del hacendado y general en desmedro del poder real de aquél. Hacia 1870 poco quedaba de los caciques pampeanos que habían habitado el escenario desde hacía cien años. La gente de la tribu, ahora seminómades, sin tierra fija que ocupar, seguían fieles al recuerdo de ese cacique que se escondía tras la fachada de un general autoritario que sumaba ganado a su peculio mientras el hambre los azotaba. 
Catriel el Viejo y sus descendientes habitaron en dos mundos a costa de mantener esforzadamente un delicado equilibrio que les permitiese ser parte de ambos. Pese a que aceptamos la nueva imagen de frontera como una franja ancha que une, y no como una línea que separa, esta premisa se hacía difícil de sostener para los caciques de la dinastía de los Catriel. El ideal, para ellos, era estar convencidos de que habitaban una franja, pero demostrarle a su gente que lo hacían en una línea. En la realidad se movían cómodamente en aquella franja, accedían a elementos y situaciones vedadas a los suyos, pero sólo por la condición de ser caciques y en presencia de un Estado débil que no podía enfrentarlos. Irónicamente, cada una de aquellas incursiones al mundo blanco los fortalecía étnicamente frente a los vecinos porteños, pero los debilitaba frente a los suyos. 